\title{
Evidencias de la existencia de una filosofía andina prehispánica tawantinsuyana
}

\author{
Dr. Alejandro Rubina López \\ allicorubina@hotmail.es \\ https://orcid.org/0000-0003-1421-7043 \\ Docente de la Facultad de Educación \\ de la Universidad Nacional "Hermilio Valdizán" \\ de Huánuco (UNHEVAL)
}

\section{RESUMEN}

La presente investigación, tuvo como objetivo evidenciar que en el mundo andino prehispánico del Tawantinsuyu, se desarrolló una filosofía andina de carácter materialista con un corpus teórico y un sistema lógico racional de pensamiento, con una estructura secuencial y dialéctico del conocimiento, cuyas evidencias constituyen los vestigios materiales y no materiales que aún existen en el territorio de Perú y Bolivia que en el pasado histórico perteneció a la sociedad andina incaica del Tawantinsuyu. El método utilizado fue el análisis filosófico y la hermenéutica, que consistió en interpretar las evidencias fácticas como las quilqas, las crónicas, el manuscrito de Warochiri, las evidencias lingüísticas y vestigios antropológicos y arqueoastronómicas que aún existen en el territorio del antiguo Perú. Los resultados de nuestra investigación, nos indican que existen vestigios materiales y no materiales, conformados por las crónicas de la época colonial, vestigios lingüísticos, antropológicos, arqueológicos y arqueoastronómicos que constituyen evidencias que en el mundo andino prehispánico del Tawantinsuyu, si existió una filosofía andina que se desarrolló desde épocas muy tempranas con fines agrícolas, pecuarios y sociales. En conclusión, es posible afirmar que existen vestigios que evidencian la existencia de una filosofía andina prehispánica, en consecuencia, hubo hombres sabios o filósofos que se llamaban yachag runa, astrónomos o quyllur watgapakug runa, hombres pesantes o yarpachakug runa. La filosofía para no caer en la especulación o elucubración mental, debe apoyarse en evidencias fácticas, por cuanto; el conocimiento surge de la realidad objetiva. 
Palabras Clave: corpus teórico; filosofía andina; yachag runa; arqueoastronomía.

\title{
Evidence of the existence of an Andean philosophy pre-hispanic tawantinsuyana
}

\begin{abstract}
The objective of the present investigation was to show that in the Andean pre-Hispanic world of the Tawantinsuyu, an Andean philosophy of materialistic character was developed with a theoretical corpus and a rational logical system of thought, with a sequential and dialectical structure of knowledge, whose evidences constitute the material and non-material remains that still exist in the territory of Peru and Bolivia that belonged to the Andean Inca society of Tawantinsuyu in the historical past. The method used was philosophical analysis and hermeneutics, which consisted in interpreting factual evidence such as quilqas, chronicles, Warochiri's manuscript, linguistic evidence and anthropological and archaeoastronomic vestiges that still exist in the territory of ancient Peru. The results of our research indicate that there are material and non-material vestiges, made up of chronicles from the colonial era, linguistic, anthropological, archaeological and archaeoastronomical vestiges that constitute evidence that in the Andean preHispanic world of the Tawantinsuyu, if there was an Andean philosophy which developed from very early times for agricultural, livestock and social purposes. In conclusion, it is possible to affirm that there are vestiges that evidence the existence of an Andean prehispanic philosophy, consequently there were wise men or philosophers who were called yachag rune, astronomers or quyllur watgapakug rune, heavy men or yarpachakug rune. The philosophy not to fall into speculation or mental lucubration, must rely on factual evidence, because; Knowledge arises from objective reality.
\end{abstract}

Key Words: theoretical corpus; andean philosophy; yachag runa; archaeoastronomy.

Artículo recibido: 20 diciembre. 2021 Aceptado para publicación: 10 enero 2022 Correspondencia: allicorubina@ hotmail.es Conflictos de Interés: Ninguna que declarar 


\section{INTRODUCCIÓN}

La presente investigación, tuvo como objetivo evidenciar que en el mundo andino prehispánico del Tawantinsuyu, se desarrolló una filosofía andina de carácter materialista con un corpus teórico y un sistema lógico racional de pensamiento, con una estructura secuencial y dialéctico del conocimiento, cuyas evidencias constituyen los vestigios materiales y no materiales que aún existen en el territorio de Perú y Bolivia que en el pasado histórico perteneció a la sociedad andina incaica del Tawantinsuyu

Las evidencias constituyen los vestigios, antropológicos arqueológicos, lingüísticos y arqueoastronómicos que aún existen en el territorio del antiguo Perú.

El dilema de la existencia de la filosofía andina prehispánica del Tawantinsuyu, nos venía preocupando desde hace bastante tiempo, por esta razón; preocupados en saber sobre la existencia de la Filosofía en el antiguo Perú o mundo andino prehispánico del Tawantinsuyu, asumimos el reto de realizar una investigación de campo a fin de identificar evidencias fácticas que contribuyan a dar credibilidad sobre la existencia de la una filosofía andina prehispánica Tawantinsuyana.

Para evidenciar los vestigios hemos utilizado en primer lugar el método de la observación que consistió en observar directamente en el campo, es decir; en la realidad objetiva, diversos elementos culturales tales como. Los quilqas con diversas representaciones, los vestigios arqueoastronómicos tales como los wankas o inti watgana, los muchkas o espejos de agua, los intis punkus o portadas del sol, etc. así mismo se utilizó el análisis filosófico y la hermenéutica, que consistió en interpretar las evidencias fácticas como las quilqas, las crónicas, el manuscrito de Warochiri, las evidencias lingüísticas y vestigios antropológicos y arqueoastronómicos que aún existen en el territorio del antiguo Perú.

Dichos vestigios culturales contienen intrínsecamente un sistema de pensamiento filosófico, un sistema conocimiento y un saber ancestral andino, lo cual se era necesario interpretarlo haciendo uso de la hermenéutica que es un método filosófico que consiste en dar interpretación a las cosas y objetos antiguos.

La técnica utilizada fue la vista de campo, la guía de observación y para registrar las evidencias se utilizó una cámara fotográfica digital.

La problemática de nuestra investigación es de carácter filosófico, se realizó por ser de interés académico, por cuanto en las aulas universitarias no solo dentro de los cursos se viene debatiendo sobre la filosofía andina, sino también en los congresos nacionales e 
internacionales, en la agenda de discusión y debate se considera como el problema de la filosofía latinoamericana prehispánica y dentro de este marco académico, está siempre presente el problema de la filosofía andina Tawantinsuyana.

En el Perú, sobre la existencia de la filosofía en el mundo andino del Tawantinsuyu, existen tres corrientes de opinión o tres puntos de vista irreconciliables que no se pone de acuerdo.

Una primera tendencia niega categóricamente la existencia de la filosofía en el mundo andino del Tawantinsuyu

La primera versión afirma que no hubo filosofía en el mundo andino prehispánico, sostiene que los runas del mundo andino no sabían filosofar, por cuanto; la actitud de filosofar es propia del mundo racional griego o mudo occidental y occidentalizado.

Los que niegan la existencia de una filosofía prehispánica, argumentan que la filosofía se caracteriza por ser un pensamiento racional, sostienen que, en el Tawantinsuyu, no hubo un pensamiento racional, opinión con la que no compartimos.

Entre los filósofos que niegan la existencia de la filosofía en el Tawantinsuyu se encuentra el destacado filósofo peruano David Sobrevilla.

Sobrevilla (1996: p.18), desde la óptica de la visión occidental y occidentalizada, sostiene que en el periodo Inca no hubo filosofía, es decir; antes de la llega de los españoles al territorio americano y peruano o antiguo Perú, no hubo filosofía, por cuanto; sus conocimientos no era de carácter problematizador, es decir; reflexivo, ni racional, era solo mitológico.

Otro que niega la existencia de la filosofía Tawantinsuyana es Gómez Pardo, R. (2010) en su artículo titulado: Pensamiento Prehispánico y filosofía: Un acercamiento desde la Hermenéutica, publicado por la revista Cuadernos de filosofía latinoamericana de Colombia, niega la existencia de una filosofía andina prehispánica Tawantinsuyana, sostiene que no es correcto afirmar que en las sociedades prehispánicas existía una filosofía. Estas en sentido estricto no filosofaron.

La segunda opinión acepta solo la existencia de una cosmovisión más no propiamente de una filosofía andina.

La segunda tesis o respuesta sobre la existencia de la filosofía prehispánica tawantinsuyana, sostiene que solo hubo una cosmovisión y mito, no acepta la existencia de una filosofía andina propiamente, aceptan solo llegaron a desarrollar una cosmovisión 
del mundo en que vivían, sostienen que los runas del mundo andino del Tawantinsuyu llegaron a tener solo una cosmovisión más no así una filosofía propiamente.

Finalmente, sobre la pregunta: ¿si hubo una filosofía en el mundo andino del Tawantinsuyu?, surge una tercera respuesta que afirma que si hubo una filosofía prehispánica tawantinsuyana.

Entre otros, los que afirman la existencia de una filosofía andina tenemos al filósofo Josef Estermann, quien sostiene que en el mundo andino prehispánico del Tawantinsuyu, si existió una filosofía andina.

Dentro de este contexto de discusión y debate de palpitante actualidad, la presente investigación no solo indaga y analiza la fuente bibliográfica, sino que principalmente identifica vestigios materiales y no materiales para evidenciar la existencia de una filosofía andina.

La filosofía andina, surge por una necesidad histórica de sobrevivencia humana, por cuanto; el acto de pensar era necesario con fines agrícolas pecuarias y sociales para continuar existiendo en el mudo andino agreste e indómito en que vivían.

Las evidencias fácticas tanto materiales y no materiales que aquí se presentan, están conformados por los vestigios lingüísticos, antropológicos, arqueológicos y arqueoastronómicos. Estos vestigios constituyen evidencias innegables de la existencia de una filosofía andina pre hispánico que se desarrolló desde épocas muy tempranas.

Los vestigios hallados, que contienen en forma intrínseca un sistema de pensamiento hemos interpretado haciendo uso del método del análisis filosófico, hermenéutico y dialéctico.

\section{MATERIAL Y MÉTODO}

El método utilizado fue la observación, que consistió en observar directamente en el campo -in situ- vestigios arqueoastronómicos, es decir vestigios arqueológicos que están relacionados con el alineamiento de fenómenos del espacio celeste andino. Estos vestigios existen en las todas las regiones del Perú prehispánico que en el pasado histórico fue el escenario geográfico del desarrollo evolutivo de los runas del mundo andino del Tawantinsuyu.

También se utilizó la hermenéutica que es un método filosófico que consiste en interpretar el significado de las cosas antiguas. La hermenéutica como un método filosófico nos 
ayudó a interpretar los diversos vestigios arqueoastronómicos que en forma intrínseca contienen un sistema de pensamiento lógico racional.

Para recoger información, se utilizó cuaderno de campo, para evidenciar los vestigios arqueoastronómicos que hemos observado en diferentes regiones del Perú, se utilizó una cámara fotográfica digital y una filmadora, cuyas imágenes se presentan en vistas fotográficas en los resultados de la presente investigación.

\section{Unidades de análisis}

\begin{tabular}{|l|l|l|}
\hline \multicolumn{1}{|c|}{ Evidencias } & \multicolumn{1}{c|}{ Lugar } & \multicolumn{1}{c|}{ Vestigio o evidencia } \\
\hline Ancash & Chavín de Wantar & Observatorio solar \\
\hline Huánuco & Waira Jirkán & Observatorio astronómico \\
\hline Ayacucho & Wari & Inti watgakun \\
\hline Cuzco & Macchu Picchu & Inti watgana \\
\hline Bolivia & Tiawanaku & Inti Punku \\
\hline
\end{tabular}

Fuente: Visita de observación a los vestigios arqueoastronómicos de Perú y Bolivia.

\section{RESULTADOS}

Los resultados de nuestra investigación nos indican que existen vestigios fácticos o materiales y vestigios no materiales o espirituales que evidencian la existencia de una filosofía andina pre hispánica Tawantinsuyana.

\section{Las evidencias constituyen los vestigios siguientes:}

1. Evidencias fácticas o materiales.

2. Evidencias no materiales o espirituales.

\section{¿Qué son evidencias fácticas o materiales?}

Se denominan evidencias fácticas a los vestigios o restos materiales, señales o huellas dejadas por el hombre, los grupos humanos o culturas en el devenir de la historia.

\section{Entre las evidencias fácticas o materiales tenemos los vestigios siguientes:}

\section{Evidencias arqueológicas}

Dentro de los vestigios arqueológicos tenemos los vestigios arqueoastronómicos.

\section{¿Que son los Vestigios arqueoastronómicos?}

Uno de los vestigios fácticos significativos que evidencian la existencia de una filosofía andina prehispánica, están conformados por los vestigios arqueoastronómicos. 
Los vestigios arqueoastronómicos son los restos arqueológicos que están relacionados con el alineamiento de los fenómenos del espacio celeste.

Las evidencias arqueoastronómicos están conformados por un conjunto de observatorios astronómicos que los hombres sabios o yachag runa del mundo andino del Tawantinsuyu, construyeron en lugares estratégicos para observar diversos fenómenos del espacio celeste andino, principalmente para observar el movimiento del Sol. Entre los vestigios arqueoastronómicos tenemos los observatorios astronómicos siguientes:

\section{Los telescopios andinos o espejos de agua}

Una de las evidencias fácticas, tangibles o materiales que acreditan o certifican la existencia de un sistema de pensamiento racional y por ende evidencia la existencia de una filosofía andina tawantinsuyana, constituyen los telescopios andinos. que son instrumentos diseñados para observar las características internas del Sol.

Estos telescopios andinos que en kichwa se denominan quyllur watgakuna, son unos morteros esculpidos sobre la superficie plana de una roca maciza que en kichwa se denomina muchka.

Estos muchkas o morteros con agua funcionan como un telescopio, por esta razón; se conoce también con el nombre de telescopio andino.

A estos vestigios arqueoastronómicos los arqueólogos llaman espejos de agua.

Los antiguos hombres sabios, filósofos, astrónomos y científicos del mundo andino pre hispánico tanto de la época inca y pre inca con estos instrumentos de observación astronómica, se dedicaron a observar las características del Sol, principalmente, observaban la mancha negra del Sol.

Los astrónomos o quyllur watgapakuy runa, del mundo andino del Tawantinsuyu, al observar al Sol con estos telescopios andinos, se dieron cuenta que el Sol tenía una mancha negra en su interior.

Se dieron cuenta que esta mancha negra crecía y decrecía cada cierto tiempo.

Se percataron que el aumento, disminución o el carácter extático de esta mancha negra solar generaba cambios climáticos que en nuestro planeta.

Con estos telescopios andinos, ubicados en lugares estratégicos, los yarpachakug runa, es decir; hombres pensantes o filósofos del mundo andino prehispánico del Tawantinsuyu, observaban la mancha negra del Sol para predecir las inclemencias del tiempo y el cambio climático con fines agrícolas, pecuarios y sociales. 
Estos telescopios andinos o quyllur watgakuna, que aún se conservan en muchos vestigios arqueológicos tanto de la época inca y pre inca, constituyen evidencias que los conocimientos astronómicos y el sistema de pensamiento filosófico desde la época pre evolucionan hasta llegar a la época inca.

Estos telescopios andinos, que se conocen con el nombre de muchkas o morteros con agua funcionan cual un verdadero telescopio, sirven para observar incluso la mancha negra del Sol.

\section{Foto $\mathbf{N}^{\circ} \mathbf{0 1}$}

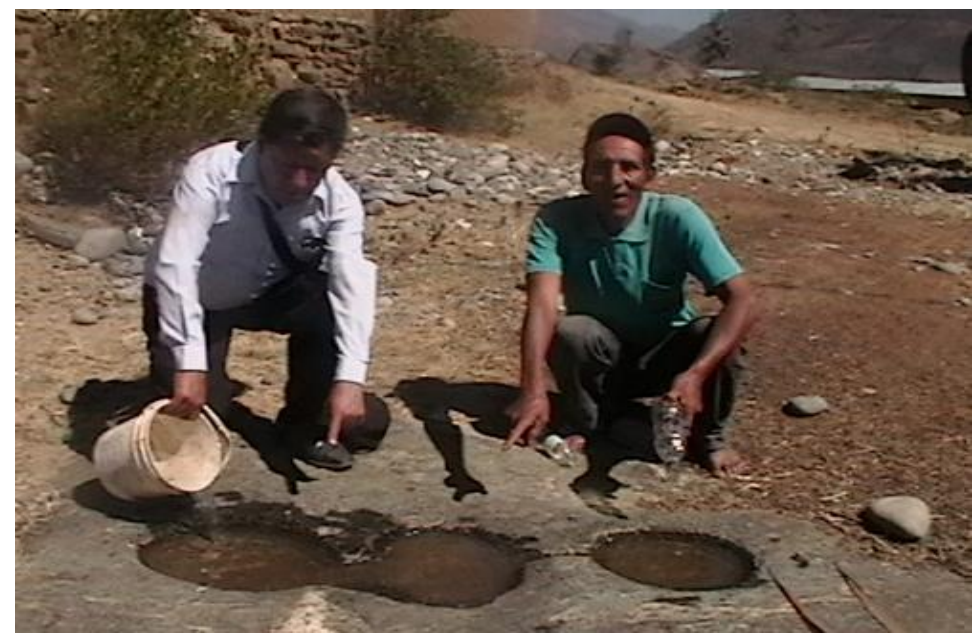

En Kotosh Wayra Jirkán de Huánuco se observa un telescopio andino del periodo arcaico.

Foto $\mathbf{N}^{\circ} \mathbf{0 2}$

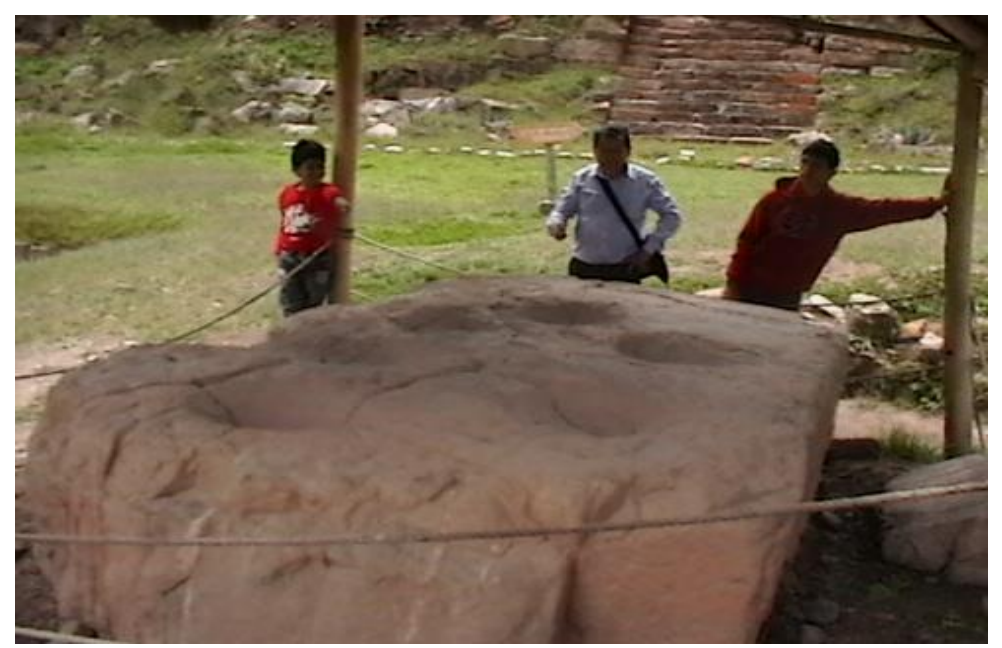

En Chavín de Wántar de Ancash, se observa un telescopio andino pre inca. 


\section{Foto $\mathbf{N}^{\circ} \mathbf{0 3}$}

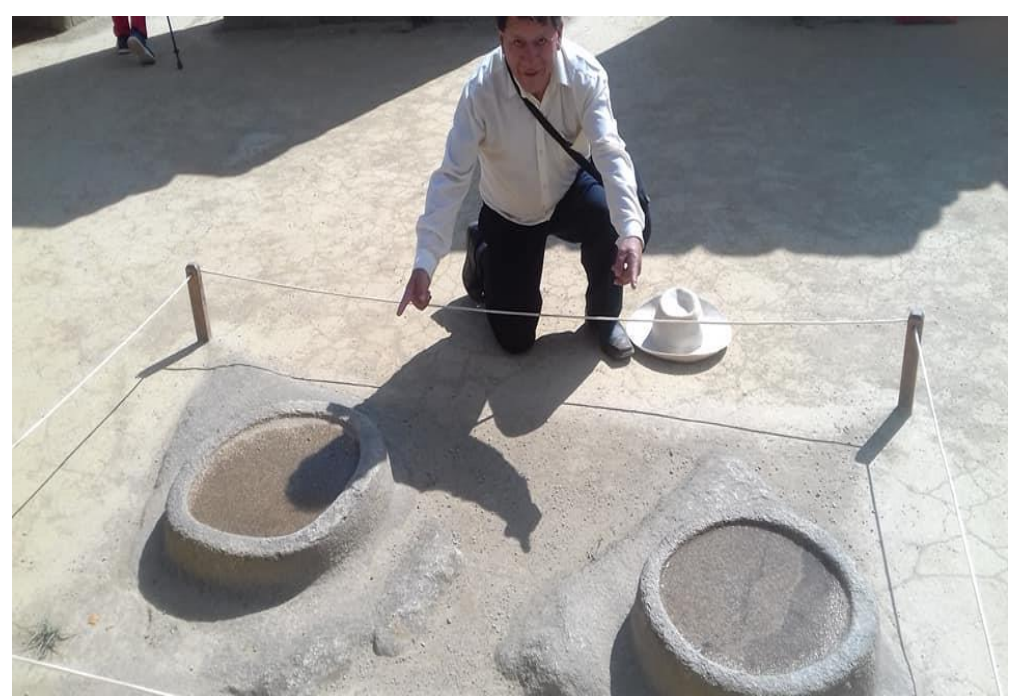

En Macchu Picchu, se observa telescopio andino de la época inca. A estos telescopios los arqueólogos llaman espejos de agua.

\section{Inti watgakuna o reloj solar}

Otro elemento cultural que constituye una evidencia fáctica o material de la existencia de una filosofía pre hispánica tawantinsuyana, constituyen los Inti watgakuna o reloj solar. Los intis watgakuna que los arqueólogos denominan reloj solar, es otro vestigio arqueoastronòmico tanto de la época pre inca e inca que aún se conservan no solo en Macchu Pichcu, sino también en muchos vestigios arqueológicos tanto de Perú y Bolivia. La palabra inti watgakuna, proviene de dos voces kichwa. Por un lado, tenemos la palabra inti que significa Sol y el vocablo kichwa watgakuna que significa observatorio. En resumen, los intis watgakuna son observatorios solares.

A estos vestigios culturales muchos arqueólogos llaman inti huatana, Traduciendo literalmente significaría amarrar o atar el sol, cuya interpretación es absurda e incorrecta. La denominación correcta es Inti watgana o inti watgakuna que significa observar al Sol o también se puede traducir como observatorio solar.

A estos instrumentos de observación solar, también se conocen con el nombre de wankas. Los wankas o inti watgakuna se encuentran en diversos vestigios arqueológicos tanto de la época pre inca e inca, incluso se observa e vestigios arqueológicos del periodo arcaico temprano, lo que nos conduce a pensar que los observatorios solares tienen un origen remoto. 
Los intis watgakuna, son piedras talladas en forma vertical de forma alargada, existen de diversas formas y tamaños, trabajados con tecnología rudimentaria y con alta tecnología, lo que nos conduce a penar que hubo permanente evolución de niveles inferiores a superiores hasta llegar a la etapa incaica.

Estos instrumentos de observación astronómica, están plantadas en forma vertical en lugares estratégicos, probablemente luego de varios años de observación han sido colocados en el lugar donde actualmente se encuentran.

Los inti wagtakuna se encuentran en todo el territorio nacional, principalmente se encuentra en el centro astronómico de Macchu Pichu con una alta tecnología, se encuentra en Cuzco.

Los wankas o inti watgakuna son instrumentos diseñados para observar la salida y puesta del Sol.

Entre el 19 y 24 de junio, los rayos del Sol reflejan por estas wankas. Cuando esto ocurre los incas se daban cuenta que estaba e un nuevo año. Era el año nuevo andino.

Entonces celebraban la fiesta al Sol que conocían con el nombre de Inti Rayme. Ese día bailaba el Sol, por cuanto, era su día jubilar.

\section{Foto $\mathbf{N}^{\circ} \mathbf{0 4}$}

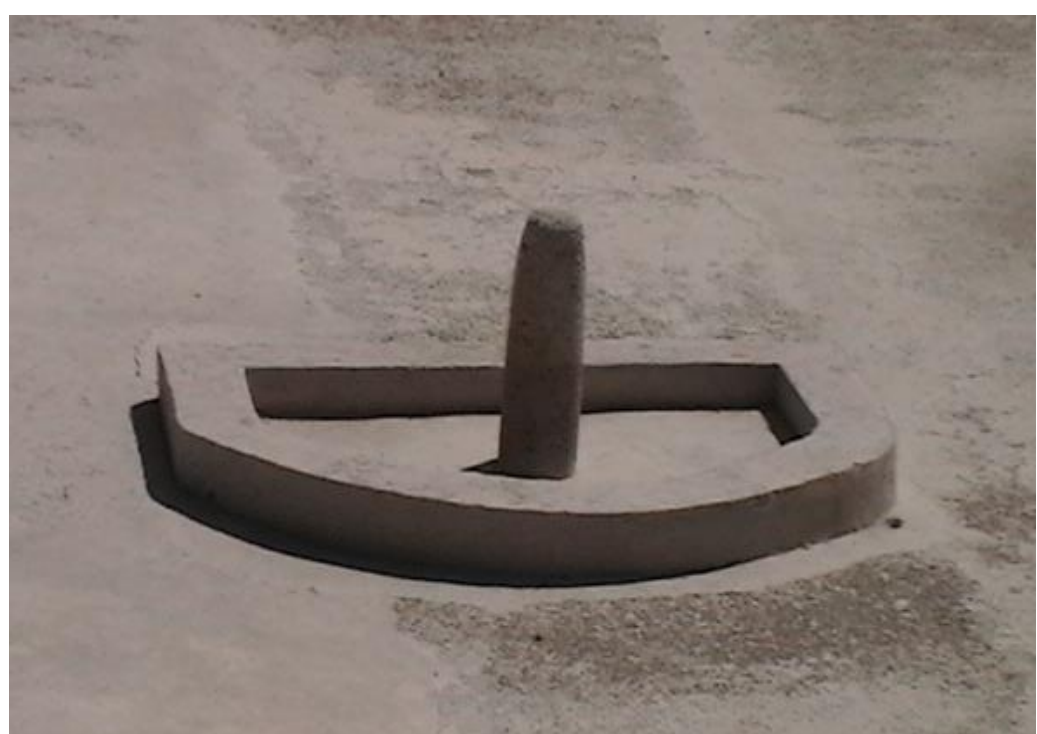

En Ayacucho en el vestigio arqueológico de la cultura Wari se encuentran dos intis watgakuna. 


\section{Foto $\mathbf{N}^{\circ} \mathbf{0 5}$}

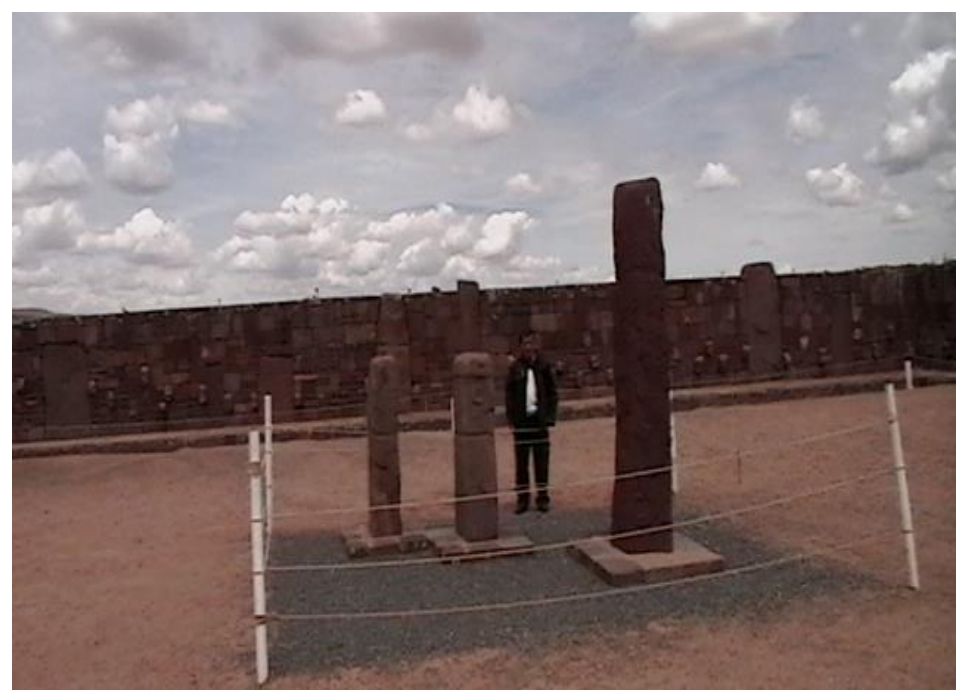

En Tiahuanaco, ubicado en Bolivia se observan tres wankas o Inti watgakuna.

\section{Foto $\mathbf{N}^{\circ} 06$}

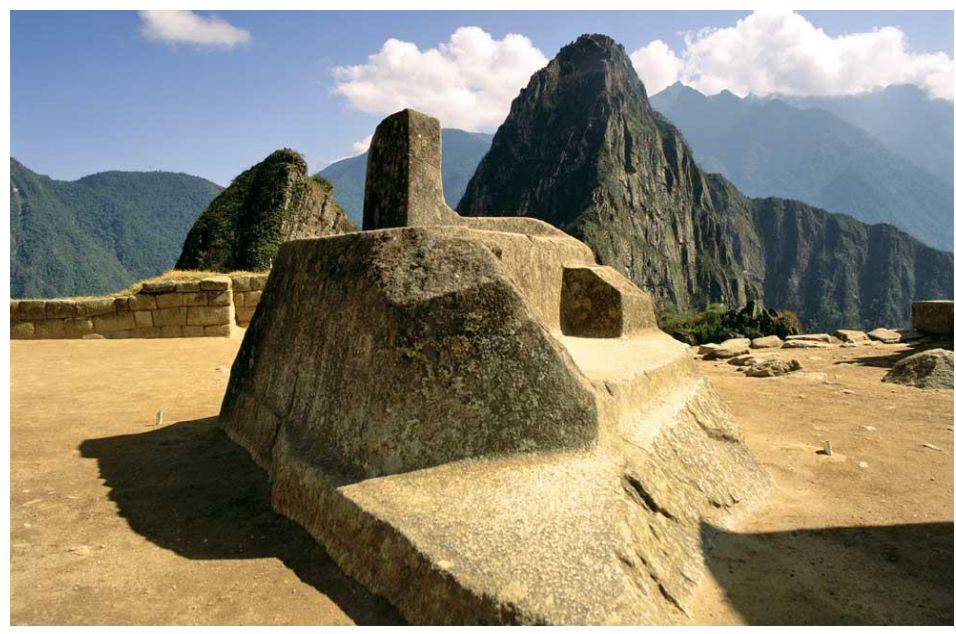

En el centro arqueoastronòmico de Macchu Picchu, en Cuzco se observa muchos observatorios astronómicos, siendo uno de ellos, los intis watgakuna o reloj solar.

\section{Los intis punkus o portadas del Sol}

Es otro vestigio arqueoastronòmico importante que constituye una evidencia fáctica de la existencia de una filosofía andina tawantinsuyana.

La palabra inti punku, proviene de la voz vocablos del kichwa, por un lado, tenemos la palabra Inti que significa Sol y otro la palabra punku que significa puerta. Traduciendo 
ambas palabras tenemos que Inti punku, significa portada del Sol o es la puerta por donde ingresa el Sol.

En efecto, estos intis punkus o porta del Sol son puertas donde ingresa los primeros rayos del Sol durante el solsticio de invierno, es decir; por estas puertas entre el 19 al 24 de junio de todos los años, al amanecer, los primeros rayos solares, por estas puertas proyecta el Sol su rayo solar.

Cuando este fenómeno ocurre, se daban cuenta que estaban en otro año, era el año nuevo andino.

Los intis punkus o portadas del Sol son vestigios arqueoastronómicos, por cuando esta relacionados con el alineamiento del Sol.

Al igual que los demás vestigios arqueoastronómicos, los intis punkus o portadas del Sol, tiene una larga historia, sus orígenes se traslada a las épocas muy tempranas del periodo pre inca. Los incas perfeccionaron estos instrumentos de observación construyendo con una tecnología mucho más avanzada, lo cual constituye una evidencia que el sistema de conocimientos y pensamiento pasado por diversos periodos de desarrollo ascensional, evolucionan a niveles cada vez más superiores hasta llegar a los conocimientos avanzados que tuvieron los yachag runa del mudo andino del Tawantinsuyu.

Los runas del mundo andino del Tawantinsuyu y otras culturas de América y Mesoamérica, como parte del sistema de sus conocimientos, lograron conocer los solsticios se producen en el momento que ocurre el quiebre de la Tierra que experimenta al girar en su eje de forma elíptica al rededor del Sol, por cuanto según el científico Kepler nuestro planeta describe un movimiento elíptico

Según Garcilaso de la Vega para observar los solsticios los Incas, construiyeron ocho torres al lado oriente y ocho torres al lado poniente que se encuentran en la ciudad del Cuzco.

Afirma que para verificar los solsticios, el mismo Inca observaba la salida del Sol, al respecto escribe: "Para verificar el solsticio se ponia un Inca en cierto puesto, al salir del Sol y al ponerse y miraba haber si salía y se ponia por entre las dos torres pequeñas que estaban al oriente y al poniente. Y con este trabajo se certificaba la astrología de los solsticios". 


\section{Foto $\mathbf{N}^{\circ} \mathbf{0 7}$}

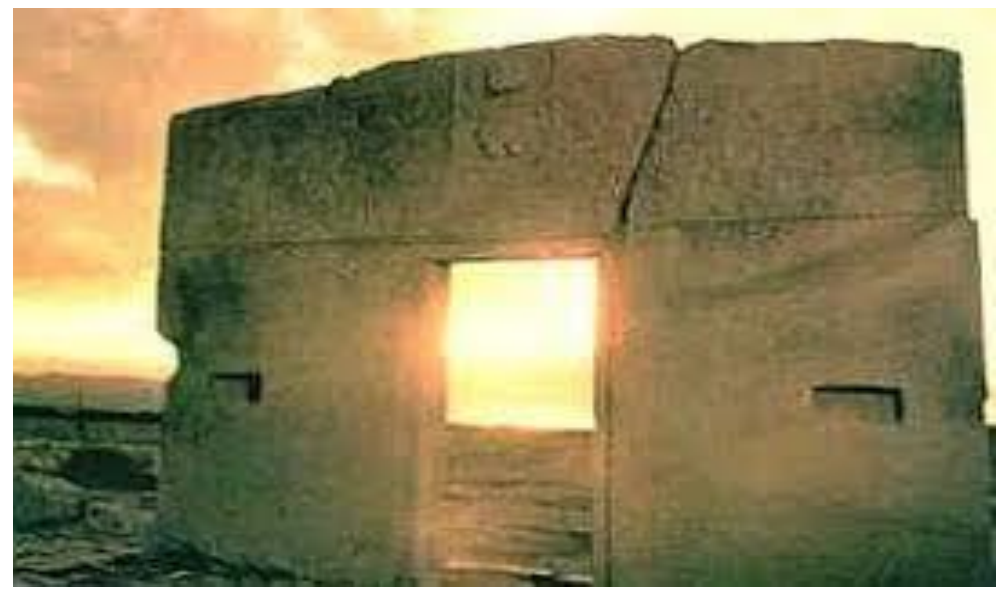

En el complejo arqueoastronòmico de Tiahuanaco, se encuentra una portada del Sol.

\section{Foto $\mathbf{N}^{\circ} \mathbf{0 8}$}

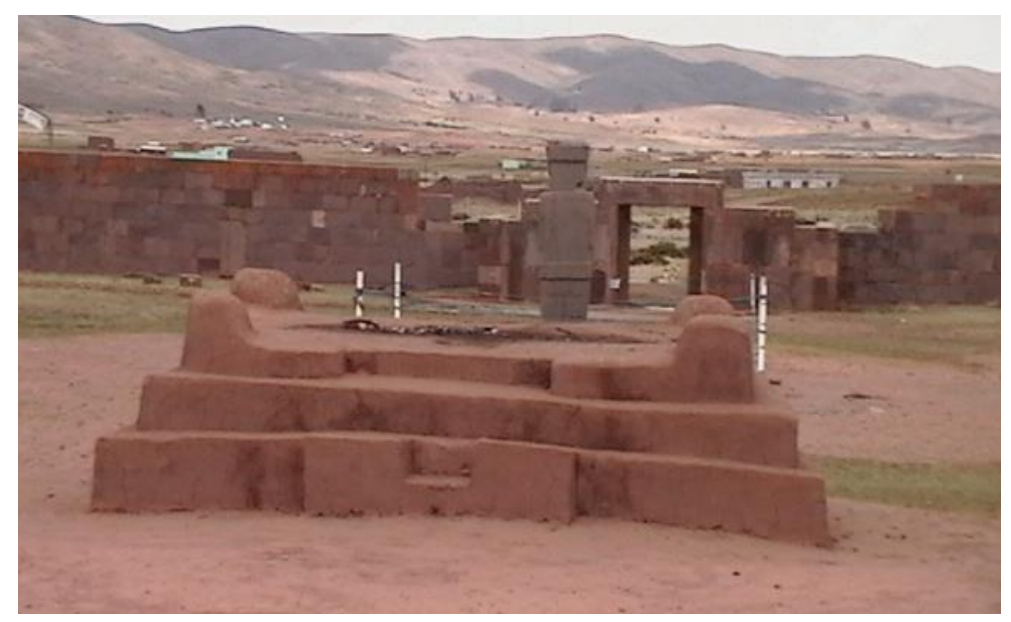

Wiracocha considerado el creador del mudo observa la salida del Sol por inti punku.

Foto $\mathbf{N}^{\circ} 09$

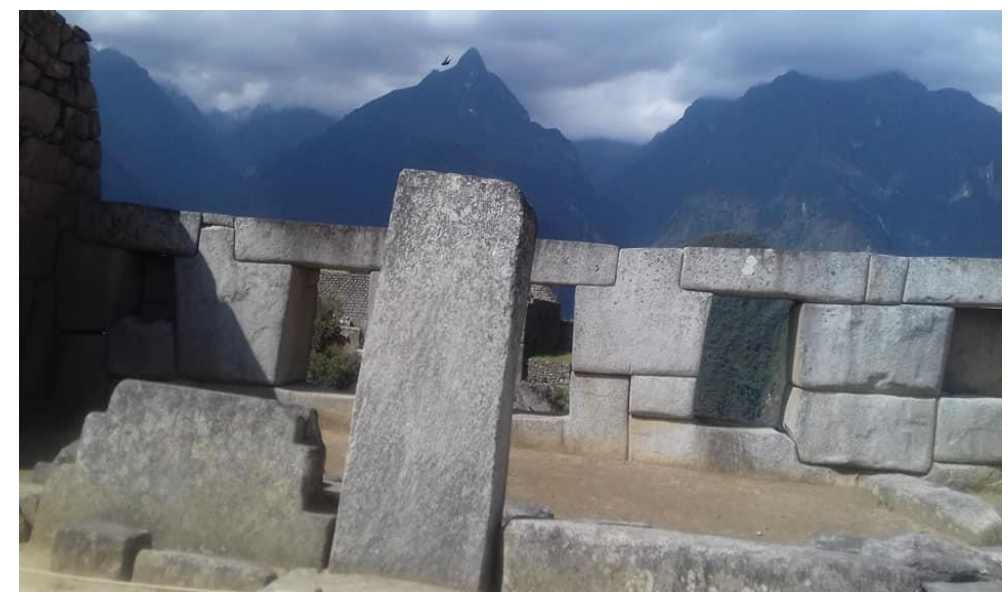

En Machu Picchu, se observa un astronómico conformado por tres ventas ubicado frente a una wanka o inti watgakuna. Por estas ventanas aparece entre el 21 y 24 de junio los rayos matutinos del Sol 


\section{Observatorios astronómicos o watgakuna}

Los runas del mundo andino del Tawantinsuyu y otras culturas de América y Mesoamérica, desde épocas muy tempranas, como parte de su sistema de sus conocimientos y pensamiento racional reflexivo, se dedicaron a observar los diversos fenómenos del espacio celeste andino. Para observar dichos fenómenos de la bóveda celeste, construyeron observatorios astronómicos, principalmente para observar durante el año el movimiento del Sol.

Casare Contreras, Orlando Josué (2017) en su articulo titulado: Del cielo al inframundo:

Observatorios astronomicos subterráneos de Mesomaerica, sostiene que las cuevas o abrigos rocosos fue la primera vivienda natural de los primerros humaos que vivenciaron hace más de 10 mil años. Este mismo lugar fue también el primer punto fijo para la observación del espacio celeste.

En la costa peruana, en la provincia de Casma en la región Ancash, se encuentra el vestigio arqueoastronómico denominado Chankillo.

Chankillo es considerado como el observatorio solar más antiguo de América, tiene una antigüedad de 2300 años.

Es un vestigio arqueológico construido sobre la cima de una colina costeña. Sobre la cima se observa 13 torres construidos de piedra. Las trece torres representan los trece meses del año.

En el mundo andino del Tawantinsuyu con fines agrícolas, pecuarios y sociales, desde épocas muy tempranas establecieron un calendario solar y lunar.

Según el calendario astronómico andino, el mes tenía 28 días, la semana 7 días, el año era de 13 meses y 364 días. No más.

Los observatorios astronómicos o los jana pacha watgakuna, se encuentran en todo el territorio peruano y boliviano, se observan de diferentes periodos y etapas históricas

José Varallanos en su libro titulado Historia de Huánuco: (1959:115) sostiene que los incas cusqueños Tupac Yupanqui y Huayna Cápac, en Wanuku Marca capital del Chinchaysuyu, entre otros fue construido un terraplén, Desde este terraplén o plataforma, los Yachag Runa del mundo andino prehispánico, observaban el alineamiento de las estrellas y los solsticios de invierno que ocurre entre el 21 y 24 de junio.

El arqueólogo José Luis Pino catedrático de la Universidad Nacional Mayor de San Marcos sostiene que durante cinco años que realizó investigación en Wanucku Marka, 
comprobó que el Ushnu de Wanuku Marca, está relacionado con el alineamiento de fenómenos cósmicos, solares, lunares y estelares,

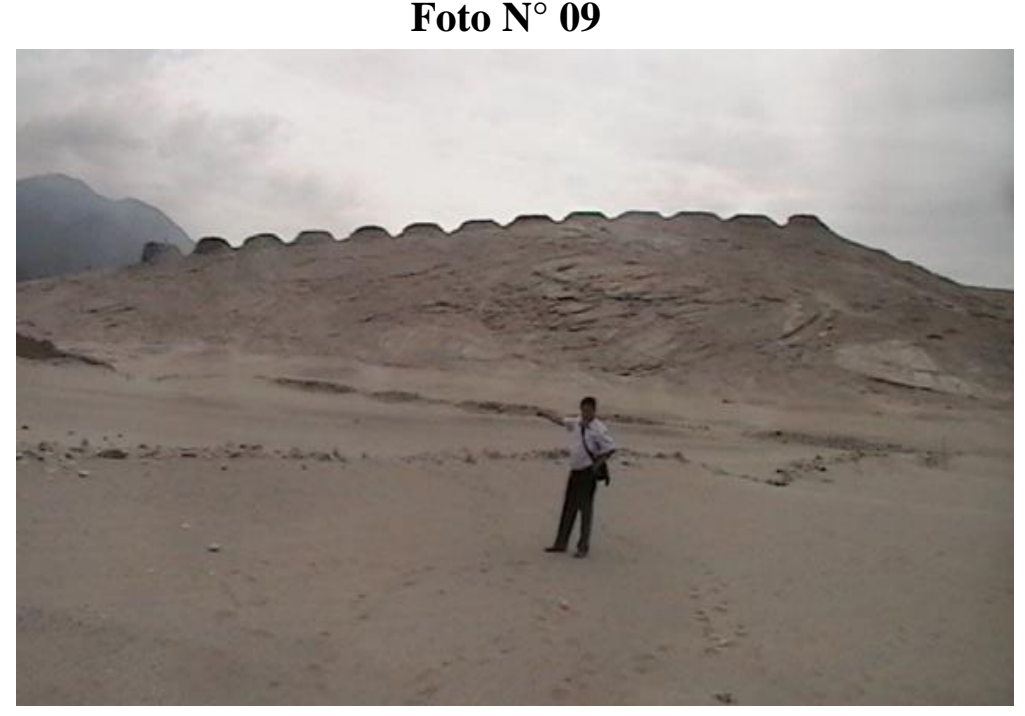

En la provincia de Casma, en el lugar denominado Chankillo el arqueólogo peruano Gezzy descubrió un observatorio Solar más antiguo de América

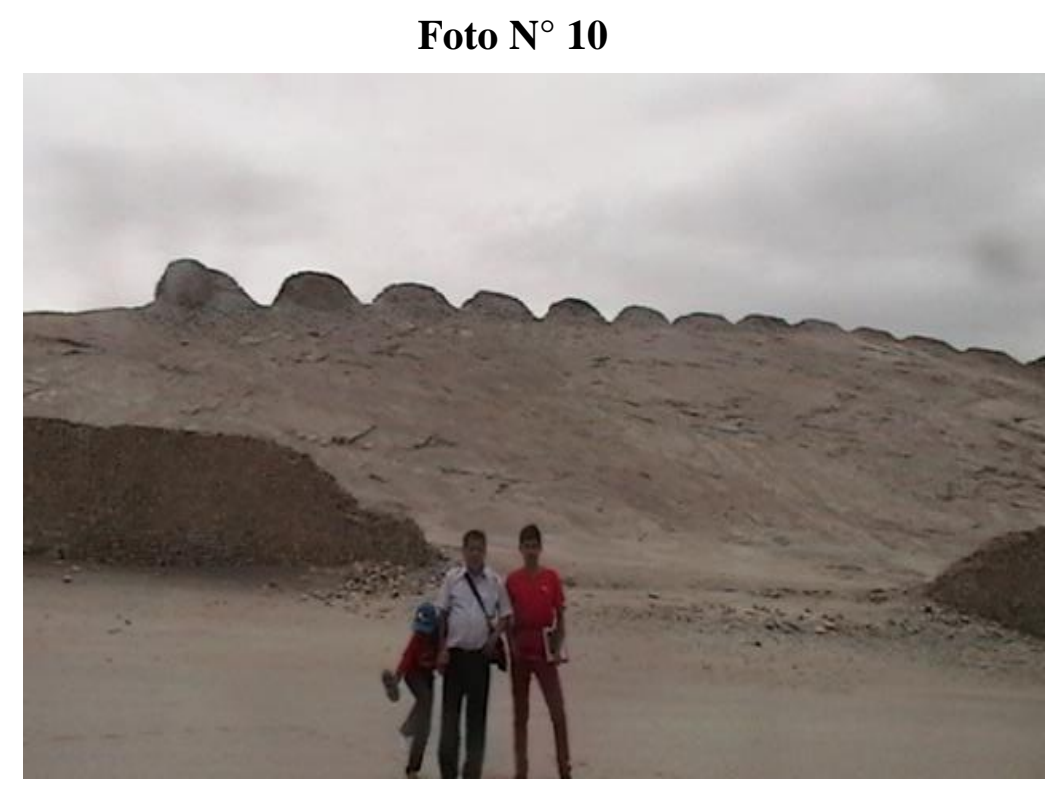

En el año 2017 tuvimos la oportunidad de visitar el observatorio solar de Chankillo 


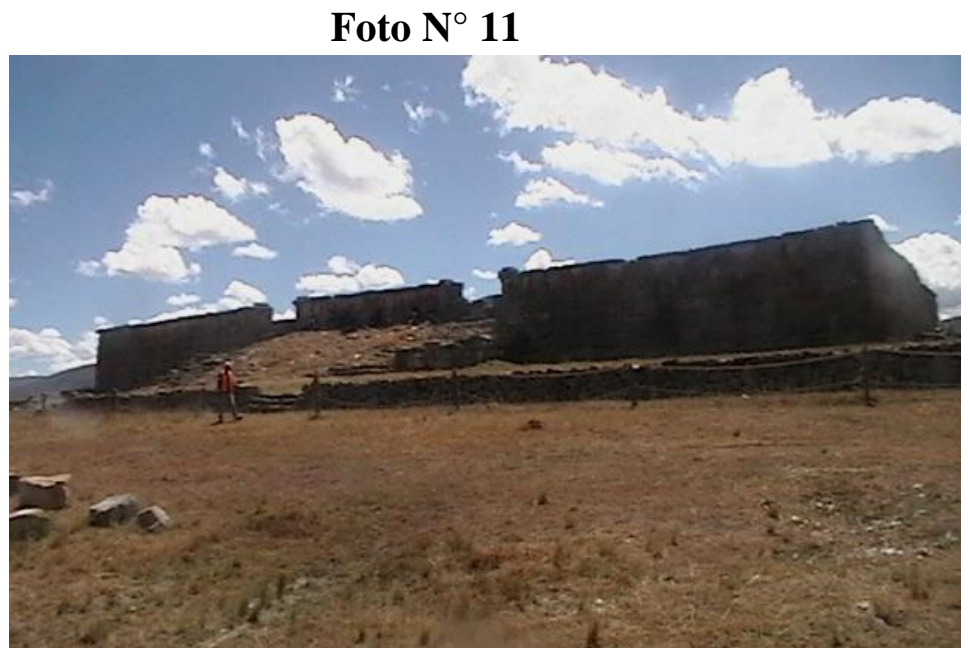

En Wanuku Marca, se observa una plataforma que fue construido con fines de observación astronómica.

\section{Foto 12}

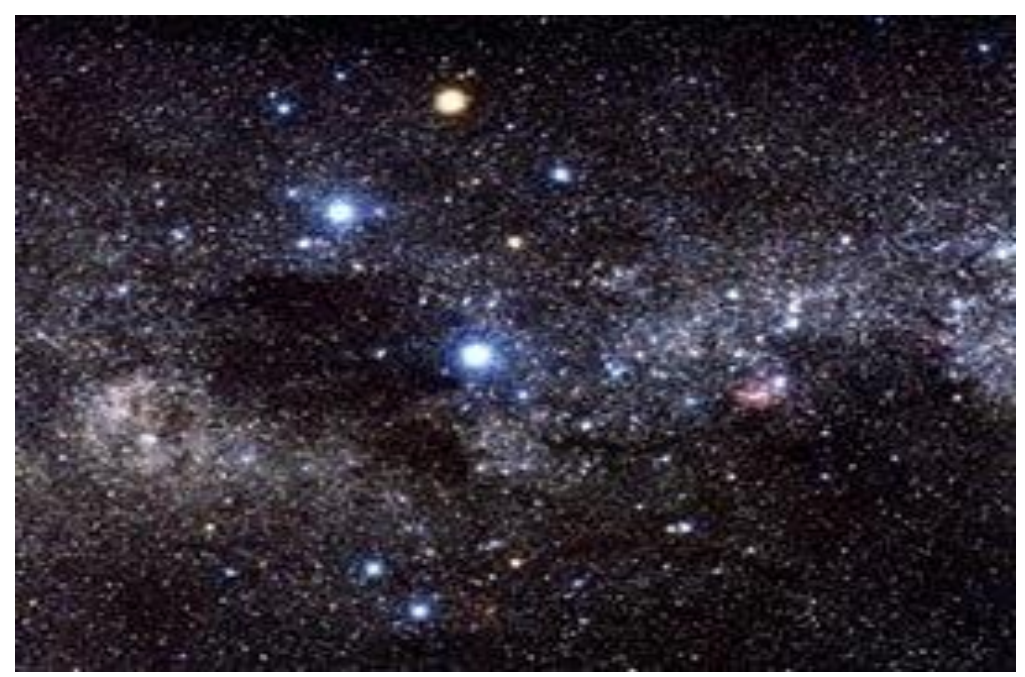

La cruz andina o chacana que se conocen, en lenguaje occidental, se denomina de cruz del Sur

Foto 13

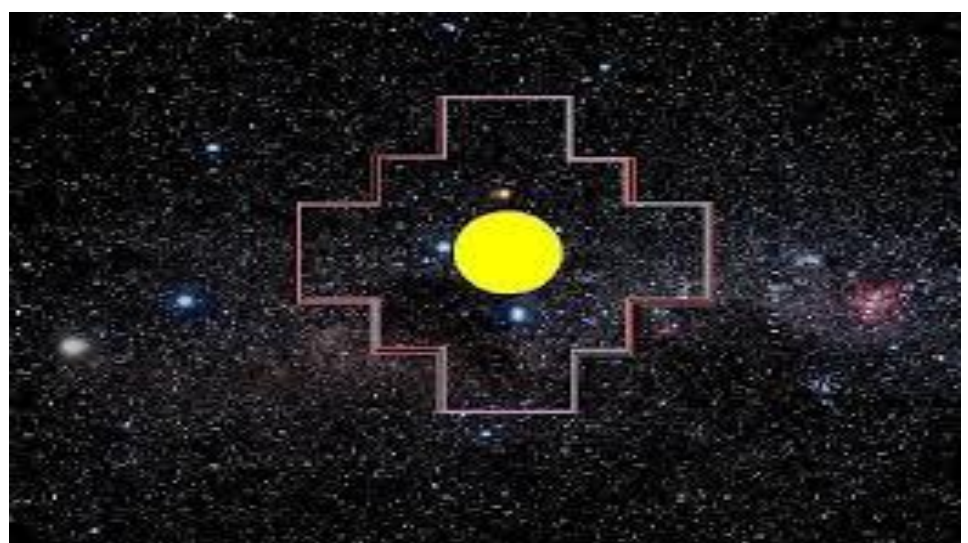

La cruz andina o chacana que observaban en el cielo andino sirvió para establecer un calendario 


\section{Foto 14}

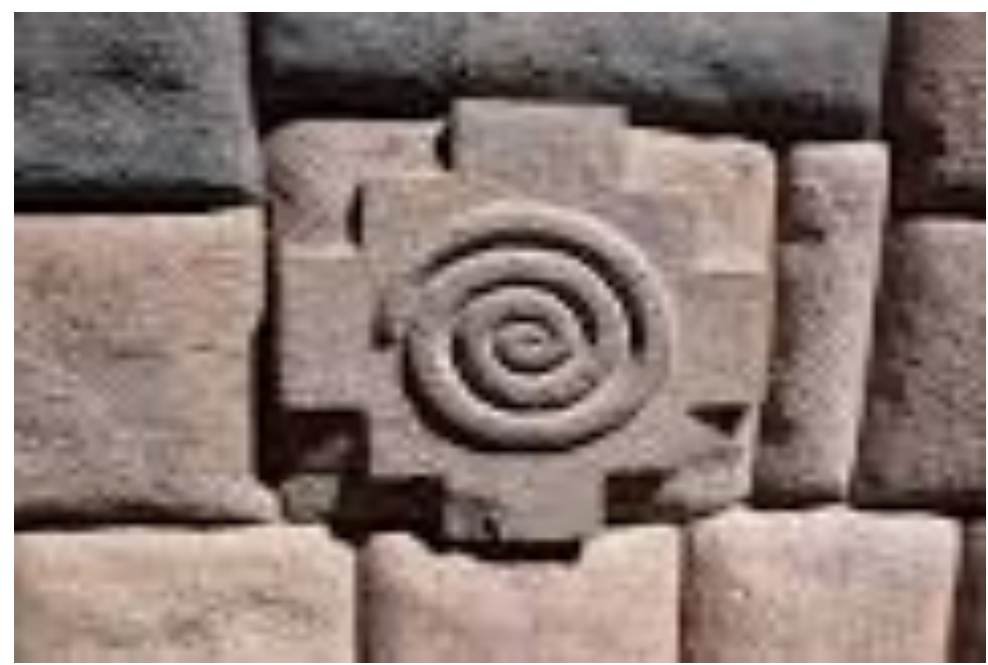

En Cusco se observa una chacana esculpido en una pared construido a base de piedra.

\section{Foto 15}

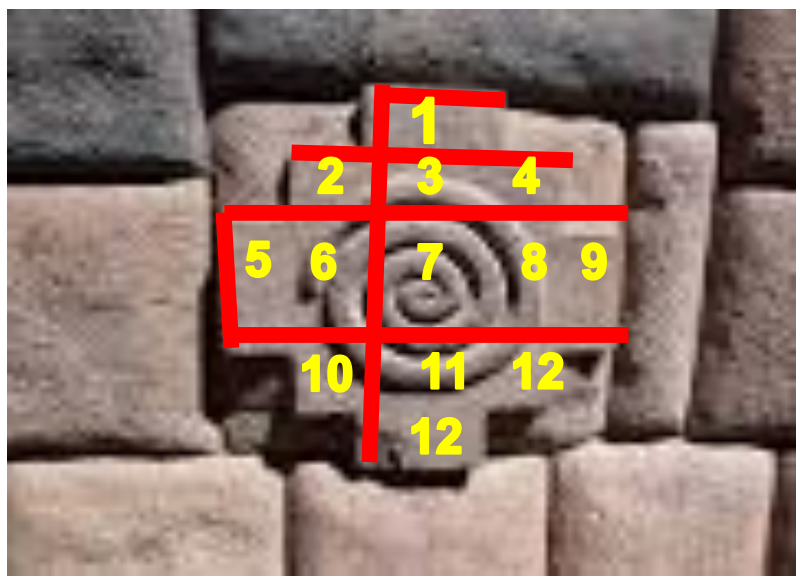

Los runas del mundo andino, observaban con reverencia diversos fenómenos del espacio celeste, observaron por ejemplo el Tayta Mayu, Cruz Andina o Cruz del Sur, el Liwyag o Galaxia, el mayu o río de estrellas que, en la astronomía moderna, se conoce con el nombre de Vía Láctea. Observaron las fases de la luna, se dieron cuenta del agujero negro o mancha negra del Sol, conocieron al planeta Venus que conocían con el nombre de warag o lucero del amanecer, conocieron el planeta Marte que llamaban Shipshin o lucero del anochecer, observaron el meneo o baile del Sol.

En base sus observaciones del espacio celeste establecieron un calendario astronómico

Colin A., Román (1969:41), sostiene que en los tiempos Prehistóricos cuando el hombre era cazador conocieron las fases de la Luna para dedicarse a la caza, al respecto 
explica: "En los tiempos Prehistóricos, cuando el hombre era cazador, debía estudiar las fases de la Luna para poder cazar de noche y necesitaba un calendario lunar para establecer fechas de celebración religiosas y tribales".

Por su parte el astrónomo norteamericano Joshep Miles Chamberlain, sostiene que los primeros calendarios estaban basados en los ciclos de la Luna, al respecto escribe: "Es difícil apreciar la influencia que ha tenido la Luna en el desarrollo de la humanidad. Iluminando la noche ha sido de positivo ayuda a los viajeros de todos los tiempos. Sus movimientos, en el cielo, rápido y fáciles de observar, dieron al hombre la base para los primeros calendarios. Los calendarios primitivos estaban basados en los ciclos de la Luna y su influencia se observa aun en nuestros días".

Los runas del mundo andino de Tawantinsuyu conocieron el calendario lunar que tienen vigencia hasta la actualidad.

El calendario lunar andino que se estableció en base a las 4 fases que tiene la Luna, el mes que conocieron con el nombre de killa, tiene 28 días. Como sabemos cada fase de la luna dura exactamente 7 días. Si multiplicamos 7 días por 4 fases de la luna, resulta que el mes tiene 28 días.

En base al movimiento de la Luna, pudieron determinar que el año tenía 13 meses que representa a las 13 lunas llenas y 13 lunas nuevas. Si el mes tiene 28 días y el año 13 meses, entonces multiplicando resulta que el año tiene 364 días y no 365 como señala el calendario occidental.

Erwin Salazar Garcés, en su libro denominado Astronomía Inka (2015:70) sostiene que el año andino tenía 12 meses. Por otro lado, Ciro Gálvez Herrera, afirma que el calendario andino tenía 10 periodos o meses. Lamentablemente ambas personalidades se equivocan, les faltó investigar en el campo de la astronomía.

\section{Evidencias no fácticas o espirituales}

Las evidencias no fácticas, o no materiales, llamadas también espirituales están conformados por elementos culturales siguientes:

\section{a). Sistema de pensamiento lógico racional.}

En nuestro artículo publicado en la revista de la Facultad de Ciencias de la Educación de la UNHEVAL denominada Identidad (2017), habíamos escrito que existen dos formas de pensamiento y dos racionalidades distintas y contrapuestas. En dicho artículo, habíamos 
afirmado, hoy nos ratificamos, decíamos que por un lado tenemos a la racionalidad andina o Tawantinsuyana y por otro la racionalidad occidental y occidentalizada.

Existen dos formas de mirar el mundo andino. Unos miran con una visión andina, con ojos andinos, en cambio hay otros que miran la realidad andina prehispánico con una visión occidental y occidentalizada

Cuando uno observa con visión andina, la herencia cultural de nuestros ancestros, vemos con admiración el notable progreso alcanzado en diversos campos del saber humano con la aplicación de una alta tecnología que ni la ciencia moderna incluso puede superarlos.

Entonces podemos señalar que esto fue producto de la razón, resultado de todo un sistema de pensamiento, se puede afirmar que fue producto de un pensamiento lógico racional y reflexivo. Es obvio que el pensamiento reflexivo, se enmarca dentro de un sistema de pensamiento filosófico y el pensar filosófico es producto de la razón humana.

Si miramos el mundo andino con una visión occidental y occidentalizada como lo hacen la mayoría de los filósofos, toda nuestra cultura, todos los conocimientos desarrollados con una alta tecnología, son considerados solo como simples mitos, nada significativo, es decir; son considerados algo así como producto de la irracionalidad, lo cual no es posible aceptar desde ningún punto de vista.

De igual forma, cuando uno mira desde una visión andina, los logros y adelantos de la cultura occidental que muchas veces choca con la ecología, las buenas costumbres, la convivencia armónica, etc., parecería que fueran obra de seres irracionales.

Desde esta perspectiva, para nuestro punto de vista existen dos racionalidades totalmente distintas y contrapuestas.

Por un lado, existe la racionalidad andina con sus propias características y visión del mundo. Por otro lado, La racionalidad occidental también con sus propias características, razones y argumentos.

Peña Cabrera, (1993: p.3-5) en su libro titulado: Racionalidad Occidental y Racionalidad Andina, explica que existen dos racionalidades y dos mundos totalmente contrapuestos: la racionalidad en el mundo occidental y la racionalidad en el mundo andino.

Gálvez Herrera, C. (2005: p.419) en su libro denominado Predicciones del Renacimiento Andino sostiene que la racionalidad andina es diferente a la racionalidad occidental, por que corresponde a hombres formados en diferentes escenarios 
Por su parte Milla Villena, C. (2008: p.38), sostiene que el racionalismo andino es totalmente contrapuesto al racionalismo occidental. Afirma que en el mundo occidental el racionalismo se sustenta en una cosmovisión regentada por la solitaria estrella Polar. En cambio, el racionalismo del mundo andino, está influenciado por la galaxia de forma espiral, llamada Vía Láctea que contiene a la Cruz del Sur o Tayta Mayu, que solamente es visible en el hemisferio sur que corresponde al mundo andino.

Desde este punto de vista, se puede afirmar que los runas del mundo andino del Tawantinsuyu para sobrevivir y continuar existiendo, para transformar un territorio andino agreste, tuvieron que hacer uso de su razón y de su conocimiento

\section{Un Corpus teórico de la filosofía andina}

Según Francisco Cobarrubias el corpus teórico se refiere a la teoría de una determinada realidad objetiva. La teoría es la explicación que sustenta un objeto o una realidad.

Desde este punto de vista, los runas del mundo andino del Tawantinsuyu, dieron explicación a cada cosa, objeto, fenómeno o proceso.

Así tenemos por ejemplo que tuvieron no solo una concepción del universo, sino también dieron una explicación teórica y dialéctica del mundo en que vivían.

Para explicar sobre el universo diseñaron una chacana que es una piedra tallada con tres escalinatas de forma rectangular.

Según la concepción y explicación andina el universo está conformado por tres mundos. El mundo de arriba o jana pacha, este mundo o kay pacha y el inframundo, mundo de abajo o ura pacha.

En la vista fotográfica de abajo se observa que el primer cuadrante de la parte superior, representa al jana pacha o mundo de arriba, la segunda escalinata del medio, simboliza a este mundo o kay pacha y la escalinata de la parte inferior o de la base representa al inframundo, mundo de abajo o ura pacha.

Foto $\mathbf{N}^{\circ} 01$

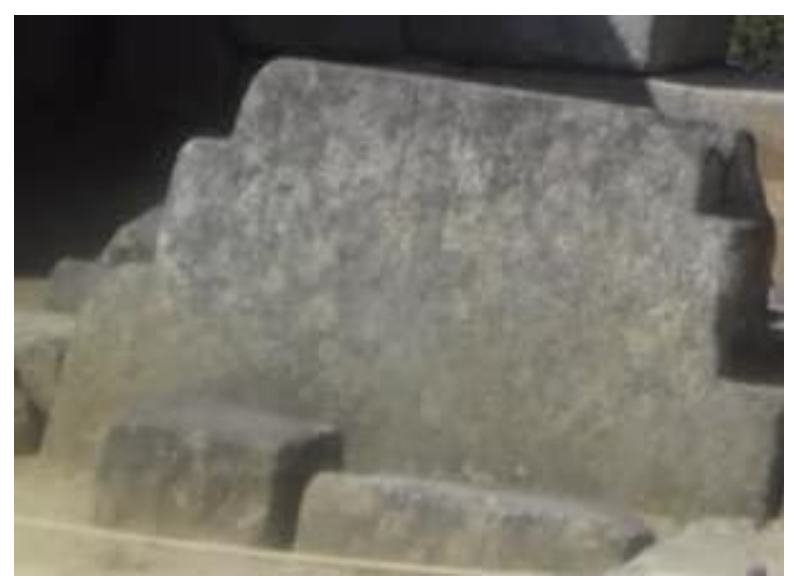


En la vista fotográfica se observa una chacana con tres divisiones o escalinatas. Estas tres escalinatas representan a los tres mundos que conforman el universo, según la concepción andina.

\section{Foto $\mathbf{N}^{\circ} \mathbf{0 2}$}

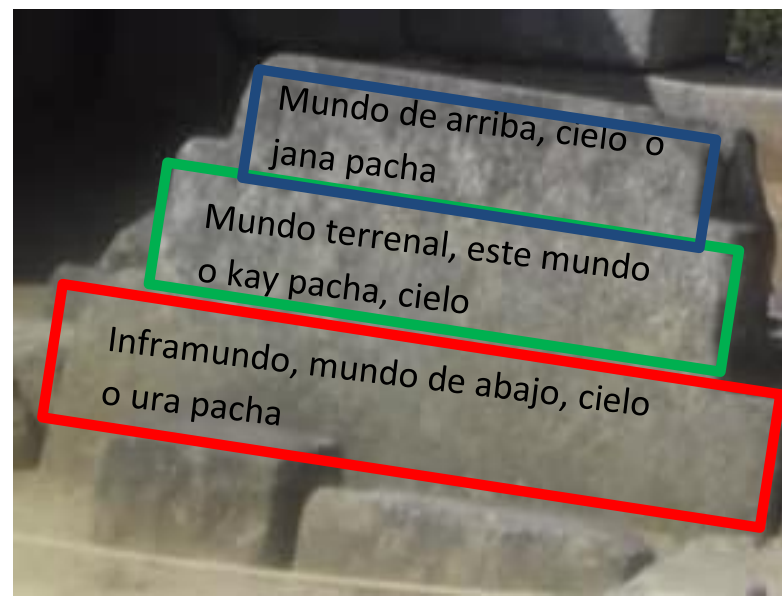

Este diseño lítico tallado sobre una roca, sintetiza todo un sistema racional de pensamiento andino prehispánico,

Las chacanas representan así mismo una estructura lógico racional del pensamiento andino y constituye una evidencia que tenían una explicación didáctica dialéctica y materialista del conocimiento, en consecuencia, la filosofía andina pre hispánico, tenían un corpus teórico.

Los runas del mundo andino tenían una concepción y explicación teórica del mundo en que vivían.

\section{Evidencias antropológicas}

Para afirmar que en el mundo andino del Tawantinsuyu, existió un sistema de pensamiento filosófico nos basamos en evidencias antropológicas.

\section{Evidencias lingüísticas.}

Las evidencias antropológicas están conformadas por las evidencias lingüísticas conformadas por los vocablos de nuestra lengua materna, el kichwa o runa shimi que están relacionados con la existencia de hombres sabios, hombres pensantes. Dichas evidencias están confirmadas por los vocablos siguientes:

- Yarpachakuy runa, equivale a gente pensante

- Musiapakug runa, significa hombres que se dedican a indagar, averiguar o investigar. 
- Wilapakug runa, equivale hombres que predicen el futuro.

- Yachag runa, equivale a hombres sabios

- Jatun yachag runa, gran hombre sabio, equivale a filosofo o científico

- Amautas, fueron los maestros.

- Camasca amautas, equivale a filósofo

- Quyllur watgapakug runa, equivale a

- Astrónomo.

- Pacha yachachig runa, maestro dedicado a la enseñanza sobre el universo.

\section{DISCUSION DE RESULTADOS}

\section{¿Existen evidencias de la existencia de una filosofía andina tawantinsuyana?}

Frente a esta pregunta, surgen obviamente dos respuestas contradictorias antagónicas o dos tendencias de opiniones contradictorias y controversiales.

La primera tendencia o respuesta será que no existió un sistema de pensamiento filosófico en el antiguo Perú.

La segunda corriente de opinión o respuesta será que sí existió un sistema de pensamiento filosófico en el Perú pre hispánico.

Esta controversia se traslada al periodo colonial del siglo pasado. En la etapa colonial se producían agrias discusiones y discrepancias irreconciliables entre el cura Ginés de Sepúlveda y el sacerdote Bartolomé de las Casas.

Ginés de Sepúlveda, un sacerdote ultra conservador, dotado de una concepción antihumana, afirmaba que los indios no tenían alma ni razón, lo consideraba como seres inferiores comparables al animal irracional, en consecuencia, era justificable la explotación de la masa indígena.

Por otra parte, el sacerdote Bartolomé de las Casas, que asume la defensa de la masa indígena, sostiene que los naturales son seres pensantes y racionales al igual que cualquier otro ser humano.

Actualmente en el pleno siglo XXI, el debate sobre la existencia o no de la filosofía pre hispánico, aún no ha sido superado, es decir: persisten las dos tendencias y discrepancias contrapuestas sobre el dilema de la existencia de la filosofía en el antiguo Perú. 
Por un lado, existen filósofos que niegan la existencia de la filosofía en el Perú antiguo, pero también hay destacados filósofos que sostienen al igual que nosotros que en el mundo andino del Tawantinsuyu, si existió una filosofía andina prehispánica.

El cronista Felipe Guamán Poma de Ayala, (1993:54) sostiene que los runas del mundo andino tuvieron asimismo filósofos y astrólogos que en base a sus observaciones de los fenómenos del espacio celeste andino, cual un filósofo o científico interpretaban y explicaban los acontecimientos que ha de ocurrir en el futuro, explica: "De cómo sabían contar los días de la luna y miraban el andar del sol y el ruedo de la del sol y la luna, miraban por la mañana el apuntar del sol y el poner del sol y para coger el fruto y romper la tierra, y poder regar la tierra y otros beneficios entendían los filósofos y astrólogos indios y de ello hasta hoy los entienden De cómo dichos filósofos, que ellos llaman Camasca Amauta Runa, entendian por las estrellas y cometas y el de eclipse del sol y de la luna, de tempestades, veían esta dichas señales y decían que había de suceder hambre, sed, muerte de gente, de buen año o mal año. Para saber sembrar escribieron sus curiosidades (observaciones)

Desde este punto de vista, se puede afirmar que existen evidencias en el todo el territorio nacional del desarrollo del sistema de conocimientos de carácter científico y un sistema de pensamiento filosófico racional que tuvieron los runas del mundo andino no sólo del Chinchaysuyu, sino también en todos los suyos o regiones del Tawantinsuyu y otras culturas andinas de América.

\section{Los incas observaban el movimiento del Sol}

Los runas del mundo andino del Tawantinsuyu y otras culturas de América y Mesoamérica, como parte del sistema de sus conocimientos astronómicos, lograron darse cuenta y conocer los solsticios.

El conocimiento de los solsticios, evidentemente constituye una evidencia de la existencia de una avanzada ciencia en el mundo andino del Tawantinsuyu.

Los yachag runa del mundo andino de Tawantinsuyu, se dedicaron a observar durante el año el movimiento del Sol para lo cual construyeron observatorios en lugares estratégicamente ubicados.

Los solsticios se producen en el momento que ocurre el quiebre de la Tierra que experimenta al girar en su eje de forma elíptica al rededor del Sol, por cuanto según el científico Kepler nuestro planeta describe un movimiento elíptico 
Este quiebre de nuestro planeta Tierra que experimenta al girar alrededor del Sol se dieron cuenta los yachag runa del mundo andino

Según la ciencia moderna, existen dos solsticios: de invierno que ocurre entre el 21 y 24 de junio y el solsticio de verano que se produce entre el 21 y 24 de diciembre.

Los Amautas, Camasca Amautas o jatun yachag Runa, que equivale al gran hombre sabio o científico del mundo andino, se dedicaban a observar este fenómeno natural para guiarse del cambio de la estación y del cambio del año.

Para observar los solsticios, los runas del mundo andino del Tawantinsuyu construyeron instrumentos de observación astronómica, tales como: Quyllur Watgakuna o espejo astronómico, Inti Watgakuna o reloj Solar, los intis punkus o portada del Sol.

El cronista Inca Garcilaso de la Vega en los Comentarios Reales (2009.:112), señala que los Incas alcanzaron a conocer los solsticios y equinoccios, al respecto, escribe: "Los Incas alcanzaron tambien a conocer los soliscitios de verano y de invierno. los cuales dejaron escritos con señales grandes y notorios".

Según Garcilaso de la Vega para observar los solsticios los Incas, construiyeron ocho torres al lado oriente y ocho torres al lado poniente que se encuentran en la ciudad del Cuzco.

Afirma que para verificar los solsticios, el mismo Inca observaba la salida del Sol, al respecto escribe: "Para verificar el solsticio se ponia un Inca en cierto puesto, al salir del Sol y al ponerse y miraba haber si salía y se ponia por entre las dos torres pequeñas que estaban al oriente y al poniente. Y con este trabajo se certificaba la astrología de los solsticios"

La palabra solsticio que proviene del latín solstitium significa Sol quieto, es decir; el Sol en un determinado momento entra en cierta quietud, como si dejara de moverse, ese fenómeno natural se llama solsticio. Los yachag runa del mundo andino tawantinsuyano se dieron cuenta de ese fenómeno natural y celebraban la fiesta al Sol.

\section{Evidencias no fácticas o no materiales}

Los que niegan la existencia de una filosofía andina prehispánica alzan su crítica, manifestando que los runas del mundo andino prehispánica del Tawantinsuyu, no pueden haber desarrollado una filosofía propiamente; por cuanto, para llamarse filosofía debe tener una estructura como tiene la filosofía griega o la filosofía moderna. 
La estructura de la filosofía griega y la occidental moderna está estructura por un conjunto de elementos racionales conformado por ejemplo por un logos, ontos, gnosis, episteme, axie. Estos elementos estructurales filosóficos, se convierten en disciplinas filosóficas.

Nosotros nos ubicamos en los que dicen sí, es decir: para nuestro punto de vista, existió un sistema de pensamiento filosófico en el mundo andino prehispánico de Tawantinsuyu. Hacemos esta afirmación, por cuanto: existen evidencias que certifican la existencia de una filosofía andina tawantinsuyana.

Entonces nos preguntamos: ¿cuáles son las evidencias que certifican la existencia de una filosofía en el mundo andino prehispánico del Tawantinsuyu?

Antes de presentar las evidencias de la existencia de una filosofía andina tawantinsuyana, primeo analizaremos los argumentos especulativos de los que niegan o dudan de la existencia de una filosofía andina en el mundo prehispánico de Tawantinsuyu.

Teniendo en cuenta, la teoría materialista del saber o del conocimiento, que indica que la fuente de todo conocimiento constituye la realidad objetiva.

Desde este punto de vista la filosofía para no caer en el plano de la elucubración mental o especulación filosófica, deben sustentarse y apoyarse en hechos facticos.

\section{Sistema de pensamiento lógico racional}

Una de las principales evidencias de la existencia de la filosofía en el mundo andino de Tawantinsuyu, es la existencia de un sistema de pensamiento racional.

El sistema de pensamiento lógico racional de la filosofía andina prehispánico, se caracteriza por la existencia de los elementos estructurales conformados por un logos, un Ontos, gnosis, episteme, axie, métodos de observación filosófica y un corpus teórico Para nuestro punto de vista, existen dos racionalidades. Por un lado, a racionalidad occidental y occidentalizada que tiene sus propias características y por otro la racionalidad andina que se caracteriza por ser distinta, contrapuesta y contradictoria a la racionalidad occidental.

\section{Existió un logos o racionalismo andino}

Logos es un término griego que fue utilizado por primera por el filósofo Heráclito y la utilizó para referirse al pensamiento, concepto, palabra, discurso y razón. Hegel llama logos al concepto, a la razón, es decir: el término griego logos, se refiere al pensamiento lógico racional del ser humano. 
Desde este punto de vista, podemos afirmar que solo la filosofía griega u occidental tuvo un logos, es decir, un sistema de pensamiento racional, sino en la filosofía andina pre hispánico hubo un logos, es decir un sistema racional de pensamiento. Un sistema de pensamiento racional desde la óptica y visión andina, totalmente diferente, contrapuesta y antológica a la racionalidad occidental y occidentalizada.

La existencia de vestigios arqueológicos y arqueoastronómicos constituyen evidencias de la existencia de un logos o un sistema racional de pensamiento en la filosofía andina prehispánico.

\section{Existió un ontos en la filosofía andina}

En el aspecto ontológico comprendían que el ser humano tenía dos dimensiones: la parte física o corporal y la parte espiritual que conocían con el nombre ánima o ánimo, es decir creían en la existencia de la vida en el más allá, por la que realizaban ofrendas a sus difuntos.

La palabra Ontos, que proviene del griego significa ser, se refiere a la ciencia del ser humano. La palabra ontos dio origen a la disciplina filosófica denominado ontología.

La ontología es una disciplina filosófica que estudia la naturaleza humana o naturaleza del ser.

La filosofía griega u occidental y occidentaliza, desde el punto de vista de la ontología filosófica, conceptúa la naturaleza del ser humano. El ser humano, según los filósofos, tiene una naturaleza que está conformado por dos dimensiones: la dimensión física o corporal y la dimensión espiritual, mental o racional.

Entonces la pregunta surge: la filosofía andina para llamarse como tal, conocieron el ontos, ese decir; entendieron y conceptuaron a la naturaleza humana.

Los runas del mundo andino entendieron con suma claridad que el ser humano estaba conformado por partes, dos entes o dos dimensiones.

Dichas dimensiones están conformadas por un lado por la física o corporal y por otro por la parte interna, psíquica o mental.

\section{La dimensión física o corporal}

Los runas del mundo del Tawantinsuyu, entendieron que eran mortales y tenía varias partes: uma, ricra, chaki, wagta, etc., 


\section{La dimensión mental o interna}

La parte espiritual, mental o psíquica que llamaban ánimo o ánima que entendieron como una energía invisible.

En la filosofía andina prehispánica tawantinsuyana, también se caracteriza por tener un sistema de conocimientos axiológicos, estéticos, epistémicos que surge y se desarrolla en el proceso de trabajo y la producción, como resultado de largas observaciones y experimentaciones metodológicas y racionales.

\section{Principios éticos y axiológicos}

La filosofía andina Tawantinsuyana al igual que la filosofía occidental, se caracterizó por la puesta en práctica de un conjunto de principios y valores éticos para la convivencia armónica, no solo entre los seres humanos, sino fundamentalmente para la convivencia entre el ser humano y la madre naturaleza.

El conjunto de principios éticos y axiológicos que pusieron en práctica los runas del mundo andino del Tawantinsuyu, estaban orientados para vivir bien dentro de la familia y la comunidad.

El alí o allí kaway o vivir bien, llapanchik allí kawashun, significa que todos debemos vivir bien en armonía no solo entre los seres humanos dentro de la familia, sino también el allí kaway significa bien en armonía con la madre naturaleza.

En el mundo andino del Tawantinsuyu, se pusieron en práctica un conjunto principios éticos y morales, entre los más importantes fueron:

- El principio de causalidad

- La reciprocidad andina

- La complementariedad

- inclusión social

- Integralidad

En base a estos principios de convivencia armónica y pacífica, los runas del mundo andino lograron un desarrollo sostenible donde no se conoció el hambre ni los escases.

\section{Principio de la causalidad}

Uno de los principios fundamentales que conocieron los runas del mundo andino del Tawantinsuyu, fue el principio de la causalidad, es decir; entendían con suma claridad que en todo problema existe causa efecto o consecuencia. 
Según la concepción andina en el mundo en que vivimos, toda consecuencia tiene causa y toda causa genera efecto.

El principio de la causalidad desde el punto de vista de la filosofía occidental, se refiere a un conjunto de ideas acerca de la relación causa-efecto.

Los runas del mundo andino entendían perfectamente que en el mundo en que vivimos, ocurren hechos, fenómenos y procesos causados por algo, que puede generar efectos o consecuencias negativas.

Según la concepción andina, el principio de la causalidad se refiere que los runas deben convivir en armonía con la naturaleza, por cuanto el desequilibrio de la naturaleza que consideraba como un ser viviente podría causar desgracias a la humanidad, razón por la que realizaban ritos y ofrendas a la madre naturaleza.

El principio de la causalidad implica, la puesta en práctica del principio de inclusión. En el mundo andino todos forman parte de la naturaleza, nadie sobra, nadie está por demás en este mundo, todos forman parte de un todo único, todos están incluidos, nadie está excluido.

Este principio de la causalidad está relacionado con otro principio ético y axiológico de complementariedad andina.

\section{El principio de la complementariedad}

El principio de la complementariedad, según la concepción andina, significa que todas las cosas, absolutamente todos tienen su complemento, lo que significa que no se puede separar artificialmente lo que la madre naturaleza ha generado este principio regulador de la vida.

El principio de la complementariedad que significa que cada cosa tiene su complemento, está interrelacionado con otros principios éticos y morales como el principio de la inclusión social.

En el mundo andino, nadie sobra, nadie está por demás todos forman parte de un todo único, todos están incluidos, por lo tanto, no hay exclusión.

Así por ejemplo a nivel macro cosmos, tenemos que Jana Patsa o cielo es complemento del Kay Patsa y viceversa.

A nivel micro cosmos, entre los seres humanos, se tiene que la mujer es complemento del hombre y viceversa. 
En mundo animal sucede lo mismo, lo cual incluso está perennizado en las configuraciones pétreas.

En la naturaleza, existen ríos macho y hembra, Urgu y china mayu, urgu puquio y china puquio, urgu turmanyuy y china turmanyuy, etc.

\section{CONCLUSIONES}

1. Existen vestigios que evidencias que en el mundo andino pre hispánico del Tawantinsuyu, se desarrolló una filosofía andina de carácter materialista con un corpus teórico y un sistema lógico racional de pensamiento, con una estructura secuencial y dialéctico del conocimiento, cuyas evidencias constituyen los vestigios materiales y no materiales que aún existen en el territorio de Perú y Bolivia.

2. Los vestigios facticos o materiales están conformados por: los muchkas, quyllur watgakuna o espejos de agua, los wankas, inti watgakuna o relojes solares, los intis punkus o portadas del Sol, los observatorios astronómicos y watgakuna.

3. Los vestigios no facticios, no materiales o espirituales están conformados por un corpus teórico con una estructura lógico racional del pensamiento, conformado por un logos, un ontos un axie y un episteme elaborados y sistematizados en idioma kichawa.

4. La existencia de un corpus teórico constituye evidencias que en el mundo andino del Tawantinsuyu, existieron hombres sabios o filósofos que estructuraron y desarrollaron un sistema de pensamiento filosófico andino con una racionalidad andina que se diferencia de la racionalidad occidental y occidentalizada.

\section{REFERENCIAS BIBLIOGRÁFICAS:}

Anticona Cebrián, J. P. (2017) La Filosofía en los incas. Lima, UNMSM.

Arguedas, J. M. (2015). Dioses y Hombres de Huarochirí, Lima. Fondo Editorial UARM.

Beauclair, N. (2013) La reciprocidad andina como aporte a la ética occidental: Un ejercicio de filosofía intercultural. Cuadernos Interculturales $\mathrm{N}^{\circ} 21$ p.39-57

Casares Contreras, O. J. (2017) Del cielo al inframundo: observatorios astronómicos subterráneos de Mesoamérica. México, Revista científica de temas regionales No. 2, pp.105-122.

Depaz Toledo, Z. (2015) La cosmo-visión andina en el Manuscrito de Huarochirí. Lima, Ed. Vicio Perfecto.

Engels, F. (1966) Dialéctica de la Naturaleza, Lima, Ed. Latinoamericana. 
Hernandez Soto, J. (2015) El Encuentro entre la Filosofía Andina y el pensar andino. Lima, UMSM.

Hostin, M. (2008) El estudio científico de los megalitos. La Arqueoastronomía. México,

Galindo Trejo, J. (2009) La astronomía prehispánica como expresión de las nociones de espacio y tiempo en Mesoamérica. México. Universidad Autónoma.

Garcilaso de la Vega (1970) Historia General del Perú. Los Comentarios Reales, T.I. Lima, Ed. Universo.

Gomez Pardo, R. (2011) Pensamiento Prehispánico y Filosofía. Un acercamiento desde la Hermenéutica. Cuadernos de Filosofía Antiamericana N 104/2011/pp.15-38.

Guamán Poma de Ayala, F. (1993) Nueva Crónica y Buen Gobierno T.I. México, Fondo de Cultura Económica.

Milla Villena, C. (2008) Génesis de la cultura andina, Lima, Ed. Amaru Waira.

Minniti Morgan, E. R. (2009) Notas sobre arqueoastronomía indígena, Córdoba-UNC

Orrego Echeverría, I. A. (2015) Descolonialización epistémica. Aportes del pensar andino abyayalanse a la filosofía. Cuadernos de Filosofía Latinoamericana Vol.36 / No.113 / pp.45.

Ortiz García, E. (2011) Los incas y el Sol: métodos de observación solar y calendario incaicos Dpto. de Física Universidad de Alcalá de Henares, Madrid (España) elena.ortizg@uah.es.

Orrego Echevarría, I. A. (2015) Descolonización epistémica. Aportes del pensar andino a la Filosofía. Cuadernos de Filosofía Latinoamericana. Vol. 36 N$^{\circ}$ 13. P.45-60.

Palacios Liberato, L. (2014), Prehispánica en los fragmentos, relatos o testimonios registrados durante la colonización española. Lima, Universidad Cayetano Heredia.

Peña Cabrera, A (1993) Racionalidad Andina y Racionalidad Occidental. Puno, CIDSA.

Pino M, J. L. (2011) El Ushnu de Huánuco Pampa y los marcadores Astronómicos. Lima, UNMSM.

Rivara de Tuesta, M. L. (1994) Pensamiento pre-hispánico y filosofía e ideología en Latinoamérica. Lima, UNM de San Marcos.

Roman Colin, A. (1972) Enigmas de las Galaxias. España, Ed. Grafica Estrella.

Rubina López, A. (2015) Interpretación filosófica de las pinturas rupestres de la región Huánuco. Imprenta gráfica Juliams. 
Rubina López, A. (2016) Conocimiento Astronómico y Pensamiento Filosófico en el Mundo andino del Chinchaysuyu. Huánuco. Imprenta gráfica Colograf.

Rubina López, A. (2018) Evolución de los machay runa, origen de la cultura Yaruwilca y runas del mundo andino del Chinchaysuyu. Huánuco, Ed. Cosmos.

Sandoval Miranda, J. G. (2018) Fundamentos Ontológicos en la filosofía andina de Josef Estermann. Bogotá Universidad Santo Tomás.

Sobrevilla, D. (1961) La filosofía contemporánea en el Perú, Ed. Carlos Mata. Lima, 1996. 